\title{
Artesanato e saberes locais no contexto do desenvolvimento local
}

Crafts and local knowledge in the local development context

\section{Artisanat et les savoirs locaux dans le cadre de développement local}

\author{
Artesanía y conocimiento local en marco de desarrollo local
}

\author{
Maria Augusta Castilho ${ }^{1}$ \\ Arlinda Cantero Dorsa ${ }^{1}$ \\ Maria Christina Lima Félix Santos ${ }^{1}$ \\ Monizzi Mábile Garcia Oliveira ${ }^{1}$ \\ Recebido em 06/03/2017; revisado e aprovado em 19/04/2017; aceito em 19/04/2017 \\ DOI: http://dx.doi.org/10.20435/inter.v18i3.1518
}

\begin{abstract}
Resumo: A pesquisa foi pautada no método indutivo, com base em artigos, documentos e entrevista realizada com a artesã Indiana Marques. Infere-se que o artesanato é uma atividade que pode ser analisada em diferentes dimensões: ambiental, histórica, econômica, social e cultural. Sendo assim, totalmente integrado ao conceito de desenvolvimento local, quando se apresenta como um caminho para o crescimento e desenvolvimento sustentável.
\end{abstract}

Palavras-chave: cultura; artesanato; conhecimento tradicional; desenvolvimento local.

Abstract: The research was based on the inductive method, based on articles, documents and interview conducted with the artisan Indiana Marques. It is inferred that handicrafts are an activity that can be analyzed in different dimensions: environmental, historical, economic, social and cultural. Thus, fully integrated with the concept of local development, when presented as a path to sustainable growth and development.

Key words: culture; handcraft; traditional knowledge; local development.

Résumé: La recherche a été basée sur la méthode inductive, sur la base des articles, des documents et entretien avec l'artisan: Indiana Marques. On en déduit que l'engin est une activité qui peut être analysé dans différentes dimensions: environnement, historiques, économiques, sociaux et culturels. Ainsi, pleinement intégré dans le concept de développement local quand elle se présente comme un chemin vers la croissance et le développement durable.

Mots-clés: culture; artisanat; les connaissances traditionnelles; développment local.

Resumen: La investigación se basó en el método inductivo, basado en artículos, documentos y entrevista con el artesano: Indiana Marques. Se infiere que la artesanía es una actividad que puede ser analizada en diferentes dimensiones: ambiental, históricos, económicos, sociales y culturales. Por lo tanto, plenamente integrado en el concepto de desarrollo local cuando se presenta como un camino hacia el crecimiento y el desarrollo sostenible.

Palabras clave: cultura; oficios; conocimiento tradicional; desarrollo local.

\section{INTRODUÇÃO}

A cerâmica é uma das principais formas de expressão cultural criada pelo homem no contato manual com a terra úmida: o barro. A cerâmica é a representação do cotidiano dos índios Terena, sobretudo das mulheres, pois o universo da cerâmica é exclusivamente feminino nessa comunidade.

A arte da cerâmica indígena é uma forma de identidade cultural, representando uma parcela da memória da etnia, e também sendo um instrumento de ser e viver o cotidiano da aldeia.

A partir da cultura indígena mesclada com outros fluxos migratórios que formam a população de Mato Grosso do Sul, percebe-se a grande tônica para o trabalho cerâmico, sendo o artesanato um modo manual de fazer da arte uma fonte crescente de renda.

\footnotetext{
${ }^{1}$ Universidade Católica Dom Bosco (UCDB), Campo Grande, Mato Grosso do Sul, Brasil.
} 
Vale ressaltar que a cultura é o ambiente simbólico de reconhecimento e identidade, o espaço compartilhado de práticas e valores e, nesse sentido, torna-se o principal elemento de agregação social para as comunidades. Assim é importante, enquanto professores de arte, conhecer os nossos bens culturais e saber qual representa um marco legal que sustenta sua preservação.

Ao ter mais contato com atividades artísticas, as pessoas se abrem para novas possibilidades e desenvolvem o capital social no território. Há que se considerar a importância da cultura como um elemento econômico. Quando o patrimônio material e o imaterial se solidificam, por meio da tradição local, o artesanato, o folclore, a música e a culinária são instrumentos utilizados em ações práticas para a geração de renda ou como atrativo turístico.

A cultura está sempre enraizada em uma base territorial, proveniente da integração do homem com a comunidade, seja ela mais fechada como a de etnias indígenas e comunidades tradicionais ou mais aberta/globalizada.

\section{CULTURA E IDENTIDADE CULTURAL}

Em uma visão contemporânea, cultura é essencialmente uma característica humana, pois somente o homem tem capacidade de desenvolver culturas identitárias.

No aporte de Geertz (1996) cultura consiste numa teia de significados que o homem tece ao seu redor e que o amarra; logo pode-se entender cultura como suporte para a adaptação do homem ao seu território.

Roberto Da Matta (2006, p. 127) propõe que:

[...] Em outras palavras, a cultura permite traduzir melhor a diferença entre nós e os outros e, assim fazendo, resgatar a nossa humanidade no outro e a do outro em nós mesmos. Num mundo como o nosso tão pequeno pela comunicação em escala planetária, isso me parece muito importante. Porque já não se trata somente de fabricar mais e mais automóvel, conforme pensávamos em 1950, mas desenvolver nossa capacidade para enxergar melhores caminhos para os pobres, os marginais e os oprimidos. E isso só se faz com uma atitude aberta para as formas e configurações sociais que, como revela o conceito de cultura, estão dentro e fora de nós.

Relacionando esses dois autores pode-se pontuar que a cultura é um processo acumulativo resultante de múltiplas experiências históricas, processo acumulado de geração a geração, desenvolvendo-se por intermédio da comunicação oral e da evolução humana na ocupação racional de seu lugar/território. Portanto a cultura favorece certamente a adaptação da vida social.

A cultura está sempre enraizada em base territorial, proveniente da integração do homem para adequar-se às adversidades do local, construindo assim sua identidade. O exemplo dessa adaptação ao território destaca-se no modo de fazer dos utensílios, seus usos e costumes. A história do artesanato tem início no mundo com a própria história do homem, pois a necessidade de se produzir bens de utilidades e uso rotineiro, e até mesmo adornos, expressou a capacidade criativa e produtiva como forma de trabalho.

A história apresenta dados e fatos de que os primeiros objetos feitos pelo homem eram artesanais. Isso pode ser identificado no período neolítico (6.000 a.C.) quando o homem aprendeu a polir a pedra, a fabricar a cerâmica, e descobriu a técnica de tecelagem das fibras animais e vegetais (HOLANDA, 2009).

A partir do século XIX, o artesanato ficou concentrado em espaços conhecidos como oficinas, onde um pequeno grupo de aprendizes vivia com o mestre-artesão, detentor de todo 
o conhecimento técnico. Este oferecia, em troca de mão de obra barata e fiel, conhecimento, vestimentas e comida (HOLANDA, 2009).

O artesanato revela usos, costumes, tradições e características de cada região. Os índios desenvolveram atividades artesanais, pode-se assinalar, rica em signos e significados, expressos pela arte da pintura- usando pigmentos naturais; também pela arte da cestaria e da cerâmica, sem esquecer a arte plumária como os cocares, tangas e outras peças de vestuário feitas com penas e plumas de aves, em diversas sociedades primitivas (DOLABELLA, s.d.).

A arte artesanal pode ser compreendida como uma expressão genuína de uma cultura que pode ser a marca de uma cultura local, pois, ao construir suas peças, o artesão expressa, por meio de uma técnica específica, o seu fazer, o seu conhecimento tácito, o qual foi acumulado das gerações pretéritas, expressividade original que marca sua cultura e territorialidade.

O enfoque desta pesquisa é o de apresentar a arte ceramista como um construto de saberes tradicionais. O modo de fazer da cerâmica terena, objeto deste estudo, é de extrema importância, a ponto de esse patrimônio imaterial ser reconhecido desde 2009, como bem imaterial do Estado de Mato Grosso do Sul, por meio do Decreto n. 12.847 (MATO GROSSO DO SUL, 2009), que reconhece a cerâmica Terena como patrimônio imaterial histórico, artístico e cultural, sendo o primeiro bem imaterial a ser registrado sob a égide da nova legislação (MATO GROSSO DO SUL, 2008).

O referido decreto de 2009 determina o registro da cerâmica Terena como patrimônio imaterial de MS, a saber:

Art. 1ำ Fica registrada a Cerâmica Terena como patrimônio imaterial histórico, artístico e cultural do Estado de Mato Grosso do Sul.

Art. 2 O O bem imaterial, Cerâmica Terena, será registrado no Livro de Registro dos Saberes, nos termos do inciso I do art. 16 da Lei no 3.522, de 2008, onde são inscritos conhecimentos e modos de fazer enraizado no cotidiano das comunidades. (MATO GROSSO DO SUL, 2009).

Pontua-se a preocupação da governança no intuito de proteger esse saber, visto que, com a globalização, os hábitos se aculturam, modificam-se e somente os planos de salvaguarda dos bens registrados são capazes de proteger e preservar esse importante conhecimento.

Laraia (2006, p. 95) assevera que:

[...] os homens, ao contrário das formigas, têm a capacidade de questionar os seus próprios hábitos e modificá-los. O antropólogo concordaria, porém, que as sociedades indígenas isoladas têm um ritmo de mudanças menos acelerado do que a de uma sociedade complexa, atingida por sucessivas inovações tecnológicas. Esse ritmo indígena decorre do fato de que a sociedade está satisfeita com muitas de suas respostas ao meio e que são resolvidas por suas soluções tradicionais.

Kashimoto, Marinho e Russef (2002) pontuam que a cultura compila um conjunto de atividades e crenças que as comunidades adotam para enfrentar as situações do dia a dia.

Já a Organização das Nações Unidas para a Educação, a Ciência e a Cultura (UNESCO, 2003) estabelece como cultura um conjunto de características espirituais e materiais, intelectuais e emocionais que definem um grupo social englobando modos de vida, direitos fundamentais da pessoa, sistemas de valores, tradições e crenças. 


\section{CERÂMICA TERENA: DISCURSO DE UMA FORÇA IDENTITÁRIA}

O Estado de Mato Grosso do Sul tem uma herança cultural que marca a sua história, ao mesmo tempo em que modela seu patrimônio natural e estabelece o modo de vida dos homens que ocuparam essa região, considerando o modo particular de ser e viver dos povos indígenas locais. Descendentes dos Txané-Guaná, descritos por viajantes cronistas no século XVII, os Terena atualmente estão mais concentrados nos municípios de Miranda, Aquidauana e Dourados, MS.

Com forte tradição na agricultura, os Terena têm no artesanato uma fonte de renda complementar. Os trançados dos abanicos, sementes nos coloridos colares são exemplos de criatividade, mas é a cerâmica a mais forte materialidade do artesanato Terena. A arte da cerâmica Terena apresenta características peculiares, grande resistência, processo de modelagem em espirais e pintura de acabamento realizada na pós-queima das peças, com motivos feitos em argila branca, florais, pontilhados, espiralados e ondulados, expressando amplas variações do repertório iconográfico Terena.

Esse repertório é um dos componentes da amálgama da identidade sul-mato-grossense. Presente nas feiras, nas ruas e restaurantes da gastronomia regional, as cores e os cheiros das vagens, do feijão, da mandioca amarela, guavira, araticum, troncos da guariroba, pequi, bocaiúva e outros ingredientes já são parte de hábitos incorporados na culinária sul-mato-grossense.

Os produtos da terra e a própria terra/barro transformada em cerâmica é uma das principais formas de testemunho de herança cultural Terena. São potes, cumbucas, travessas e figuras zoomórficas com delicados adornos florais e pequenos traços geométricos que seduzem e encantam pela beleza e singularidade.

Ao retomarmos as referências históricas concernentes ao papel da arte do barro nas civilizações primitivas, percebe-se que a função utilitária desses artefatos antecede ao decorativo. A cerâmica sempre fez parte da história da humanidade, vocábulo originário do grego "kéramos" ("terra queimada" ou "argila queimada") é um material de grande resistência, que tem servido para rememorar civilizações, sendo encontrado em muitas escavações arqueológicas (SOUZA, 2000).

A cerâmica é uma atividade de produção de artefatos a partir da argila, material fácil de moldar quando umedecida. Desde a antiguidade até hoje, a forma rudimentar de fabricação de instrumentos utilitários a princípio é a mesma. Resume-se em moldar e submeter a peça produzida a uma secagem para retirar a maior parte da água; posteriormente, o objeto modelado é submetido a altas temperaturas (ao redor de $1.000^{\circ} \mathrm{C}$ ), que lhe atribuem rigidez e resistência mediante a fusão de certos componentes da massa e, em alguns casos, fixando os esmaltes na superfície. Essas propriedades permitiram que a cerâmica fosse utilizada na construção de casas, vasilhames para uso doméstico e armazenamento de alimentos, vinhos, óleos, perfumes, e até na construção de urnas funerárias (SOUZA, 2000). Atualmente a cerâmica pode ser uma atividade artística, em que são produzidos artefatos com valor estético, ou uma atividade industrial, em que são produzidos artefatos diversos.

Segundo Lima (1987), a cerâmica indígena brasileira está ligada à área doméstica, constituindo domínio quase exclusivamente feminino, e a mulher Terena, exceto na estação chuvosa ou em lugar de difícil acesso, tem o auxílio masculino na coleta do barro.

"Em dia que se vai fazer cerâmica não se vai para a cozinha", afirmação da ceramista Terena. Trata-se aqui do cuidado em isolar o barro, que será cerâmica após a queima, da ação deletéria do sal. Esse saber cultural é passado de geração a geração, representa um modo de fazer dessa etnia (MATO GROSSO DO SUL, 2009). 
Como uma cultura milenar, a confecção das cerâmicas Terena segue o calendário lunar e está pautada em muitos detalhes e segredos:

- A argila para a modelagem não pode ser coletada em semana de lua nova, conforme relatado pelas índias: 'o barro coletado em lua nova não produz uma boa cerâmica';

- As artesãs Terena não podem consumir alimentos durante a produção das peças, principalmente pães e alimentos que contenham farinha;

- Antes de manusear a argila, as Terena devem banhar-se, a fim de evitar que o suor se misture à matéria prima e prejudique a peça. (SOUZA, 2000, p. 38).

É também vetado às Terenas confeccionar cerâmicas se estiverem menstruadas.

Todos esses cuidados fazem com que as peças saiam perfeitas, eliminando a perda durante o processo de queima. Inicialmente as mulheres Terena produziam peças decorativas, pequenos animais e também utensílios indígenas, mas hoje já seguem o fluxo do mercado e fazem grande quantidade de peças em diversos formatos e tamanhos para atender a uma demanda ainda incipiente (Figura 1).

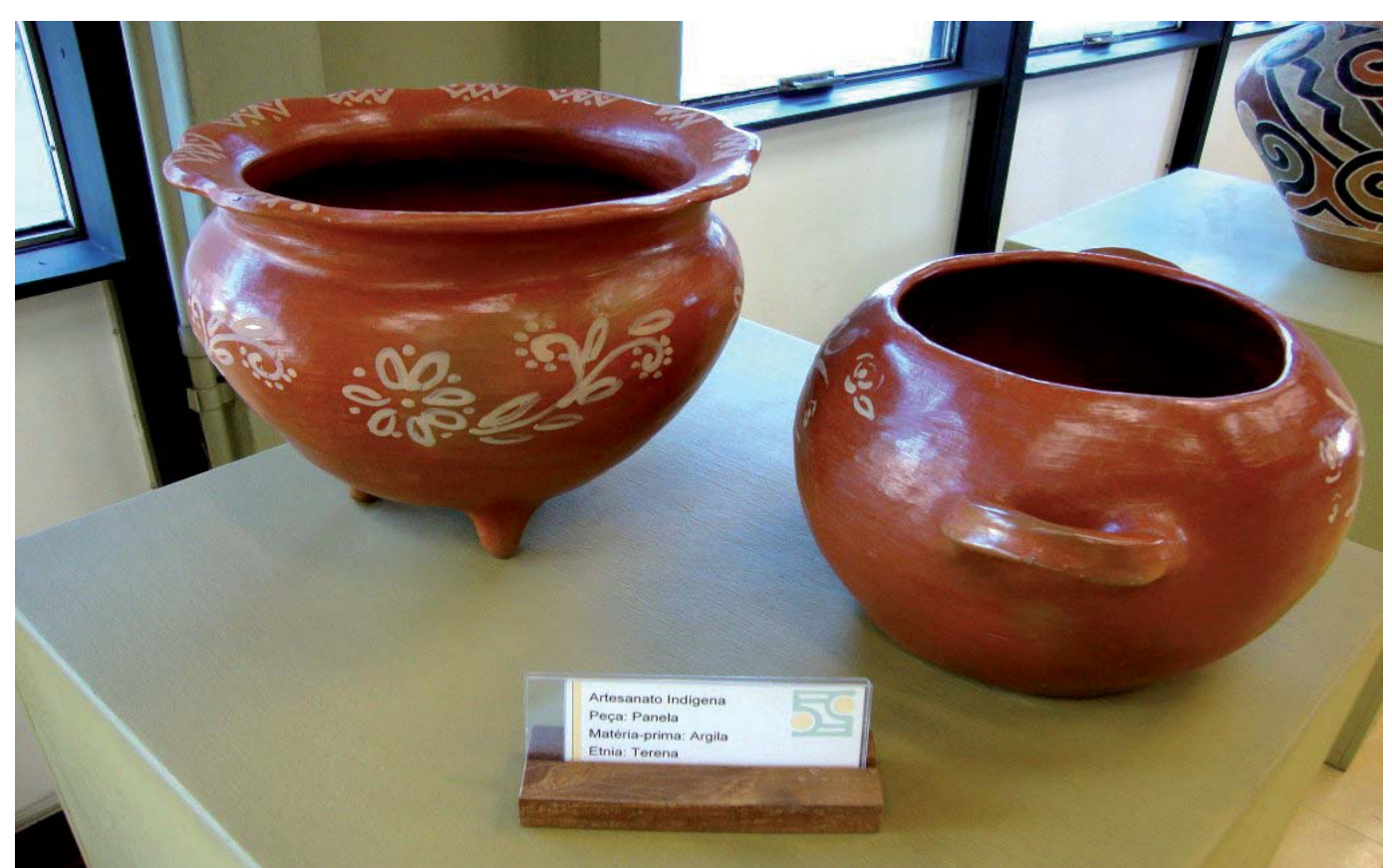

Figura 1 - Utensílios criados pela mulher Terena

Fonte: Acervo Fundação de Cultura de MS (2014).

A divulgação e a comercialização da arte em barro Terena desde a instalação do Estado de MS, em 1979, continuam praticamente na mesma configuração quanto a sua distribuição, ou seja, a índia Terena traz seus produtos até a Casa do Artesão em Campo Grande, unidade da Fundação de Cultura de MS (FUCMS), e atendendo principalmente aos turistas. Em Miranda, há o Centro Referencial de Cultura Indígena, localizado na rodovia por onde param os que se dirigem ao Pantanal e à região de Bonito. Aquidauana, com o retorno do Trem do Pantanal, reavivou a Feira Indígena ao lado da Estação. Em Campo Grande, tem a Feira Indígena ao lado do Mercado Municipal, onde a cerâmica Terena se mistura ao colorido das mudas de avenca, samambaias, orquídeas, milho, mangas etc. O Memorial da Cultura Indígena na Aldeia Urbana Marçal de Souza é outro exemplo de ponto de comercialização desses artesanatos. 
Na tentativa de mesclar linguagens, pode-se citar o trabalho da artesã Indiana Marques que apresenta suas bugras, que carregam os minipotes Terena. Nesse caso, tem-se um produto feito por duas artesãs com linguagens artísticas bem demarcadas. Não há um consenso quanto ao valor estético ou valor cultural agregado, mas é mais uma opção que contempla a função decorativa.

Outro ponto a se destacar é o plano de salvaguarda, que consiste em ações concretas que contribuem para a sustentabilidade do bem imaterial registrado. Não basta a sociedade eleger determinado produto cultural como representativo de sua cultura, se isso não vier acompanhado de um planejamento que viabilize comportamentos que promovam socialmente o grupo responsável pelo bem. A cerâmica Terena é um elemento agregador junto com a Língua Terena, colaborando de forma significativa para a preservação de a herança cultural de MS. Alguns exemplos de salvaguarda: souvenir para empresas, congressos, peças de decoração para rede hoteleira, restaurantes.

A cerâmica Terena, testemunho cultural dessa etnia representa, antes de tudo, um discurso de resistência, passado de geração em geração, e sendo um exemplo vivo da força identitária construída pelas mãos sábias de mulheres que perpetuam modos e saberes. Do barro a beleza, do barro a singeleza, do barro a subsistência, do barro a fala que silencia no ato de generosidade em compartilhar a cultura que é de quem produz e de quem a utiliza em novos contextos. E é nessa dinâmica materializada pela cerâmica Terena que velhas e novas identidades vão se construindo. Que essa construção tenha um percurso marcado cada vez mais pela promoção e integridade do teor histórico-cultural do bem imaterial-cerâmica Terena- voz que ecoa e se enraíza no fortalecimento da identidade sul-mato-grossense.

\section{CULTURA LOCAL - O FAZER DA ARTESÃ INDIANA MARQUES}

Indiana Marques nasceu em 1958, em Ponta Porã, na fazenda de erva-mate de seu pai. Sua mãe era formada em Belas Artes e, de modo indireto, influenciou suas filhas em fazer da arte suas brincadeiras do cotidiano. Além de Indiana Marques, sua irmã Araci Marques Vendrami, é também artesã reconhecida atualmente em Mato Grosso do Sul, por suas peças voltadas principalmente para o artesanato indígena (FCMS, 2008).

Indiana Marques casou-se cedo, aos 17 anos, e foi morar em Campo Grande. Aprendeu a modelar o barro extraído das barrancas dos rios e, fazendo seus brinquedos, construiu sua identidade de artesã (PELEGRINI, 2011). Trabalhando com artesanato há muitos anos, tem sua vocação na cerâmica, pois, após participar de muitas feiras de artesanato pelo Brasil e de elaborar bonitos trabalhos com cerâmica - utensílios domésticos, como travessas e aparelhos de jantar-, pensou e criou uma escultura representativa do estado de Mato Grosso do Sul abordando essa fase. Seu artesanato atual tem o foco na representação humana, modelando a figura da mulher de etnia indígena (MARQUES, 2008).

Em 2006, ganhou o prêmio do SEBRAE, Top 100, que destacou os melhores artesãos do país. Suas "bugras de cerâmica" são vendidas em 30 lojas, espalhadas por todo o país. Atende a grandes marcas como a Natura, e algumas esculturas suas já foram exportadas para Itália, Portugal e outros países da Europa (ZURUTUZA, 2011). Suas esculturas em cerâmica, "bugras", como a artista mesmo chama, pode ter de 20 centímetros de dimensão a 1 metro e meio. Com a crescente procura por seu trabalho, Indiana aliou-se a famílias indígenas para produzir em 
grande escala e atender as suas encomendas (MARQUES, 2008). Em parceria com três famílias Terena, do município de Miranda, MS, a artesã compra as peças dos adornos das cabeças de suas esculturas das índias e paga à vista. Há nessa ação um pequeno exemplo de desenvolvimento local, pois oportuniza às mulheres Terena um ganho fixo ao mês e uma forma de salvaguardar o seu saber- o modo de fazer da Cerâmica Terena, patrimônio imaterial de Mato Grosso do Sul, reconhecido por decreto estadual, no ano de 2009.

Segundo relato da artesã Indiana Marques,

As índias Terena produzem moringas em três tamanhos padronizados, pequeno, médio e grande-adornos para a cabeça das bonecas, "bugras".- Elas são fantásticas! E o fato de produzirem esses pequenos detalhes em minhas peças, dá nova interpretação às esculturas. Antes eu mesma fazia as miudezas, vasinhos, milhinhos, frutinhas, era muito trabalhoso e com o crescimento da demanda, foi uma forma de continuar a produzir sem descaracterizar meu artesanato. ${ }^{2}$

Indiana reconhece no artesanato um negócio em expansão e resume a sua arte com a frase: "Sou feliz com o que faço". Um fato curioso é o de que o nome de batismo da artesã tem relação direta com o seu objeto de trabalho, e a integra quase que naturalmente em sua arte de ceramista, as índias (Figuras 2 e 3 ) produzidas por ela fazem sucesso e ilustram a decoração de cada espaço, com um pouco da cultura de Mato Grosso do Sul.

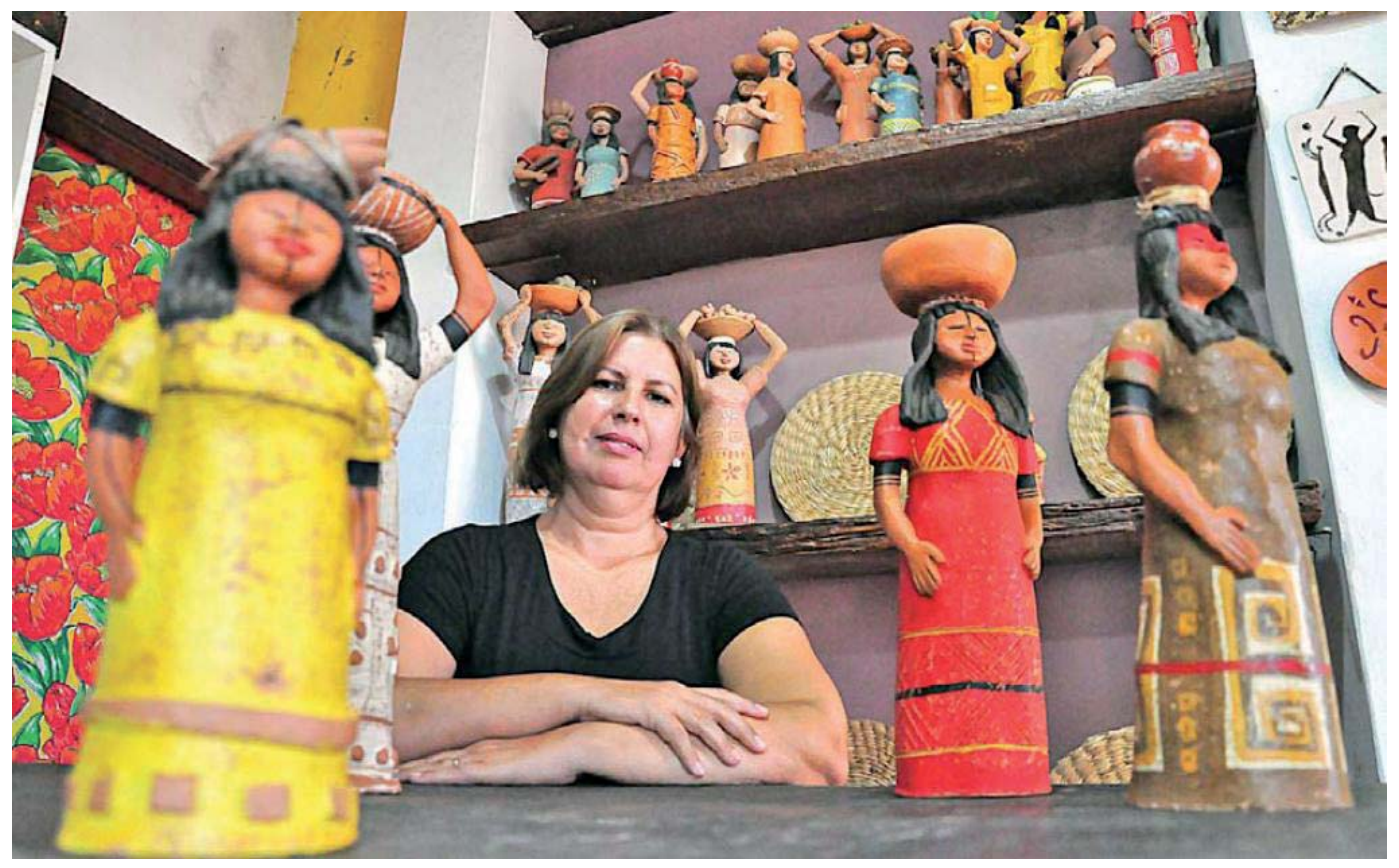

Figura 2- Indiana Marques junto às índias que fabrica Fonte: FMCS (2016). Foto: Edemir Rodrigues.

\footnotetext{
${ }^{2}$ Entrevista concedida por Indiana Marques, da Fundação de Cultura de Mato Grosso do Sul, via telefone, em 05/05/2016, às 14h, a Maria Christina de Lima Félix Santos.
} 


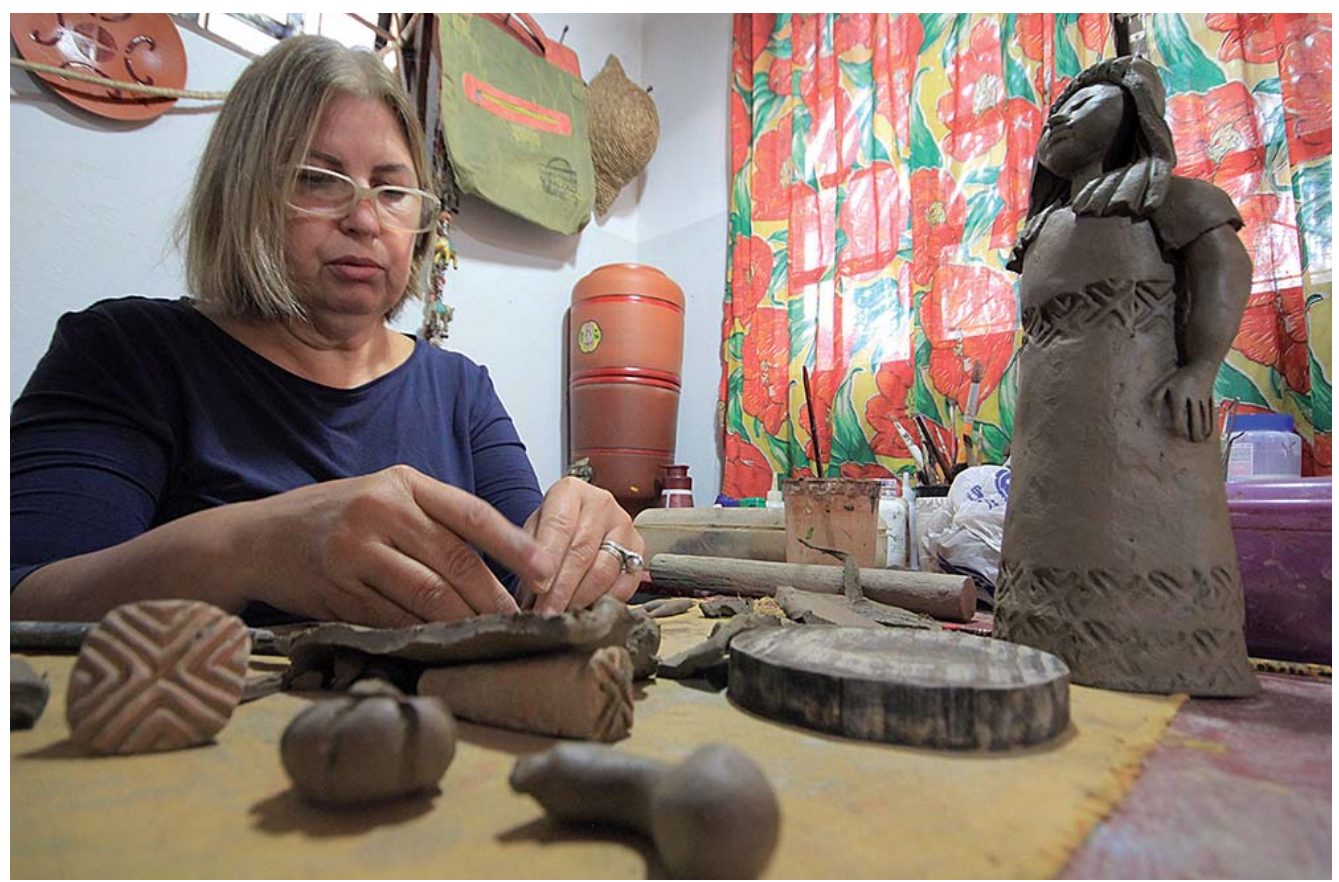

Figura 3- Indiana Marques trabalhando com argila Fonte: FMCS (2016). Foto: Edemir Rodrigues.

O artesanato comercial, decorativo de Indiana Marques e a arte da cerâmica Terena se mesclam em muitos contornos, e a produção crescente da artesã possibilita a perpetuação do saber, repassada pela história oral das aldeias sul-mato-grossenses. A Cerâmica Terena, exemplo de uma cultura milenar, que sofre as modificações e interferências da cultura globalizada e que precisa ser transmitida dentre as mulheres terenas para a preservação e, assim, para que as práticas culturais e expressões não desapareçam (Figuras: 4, 5, 6 e 7).

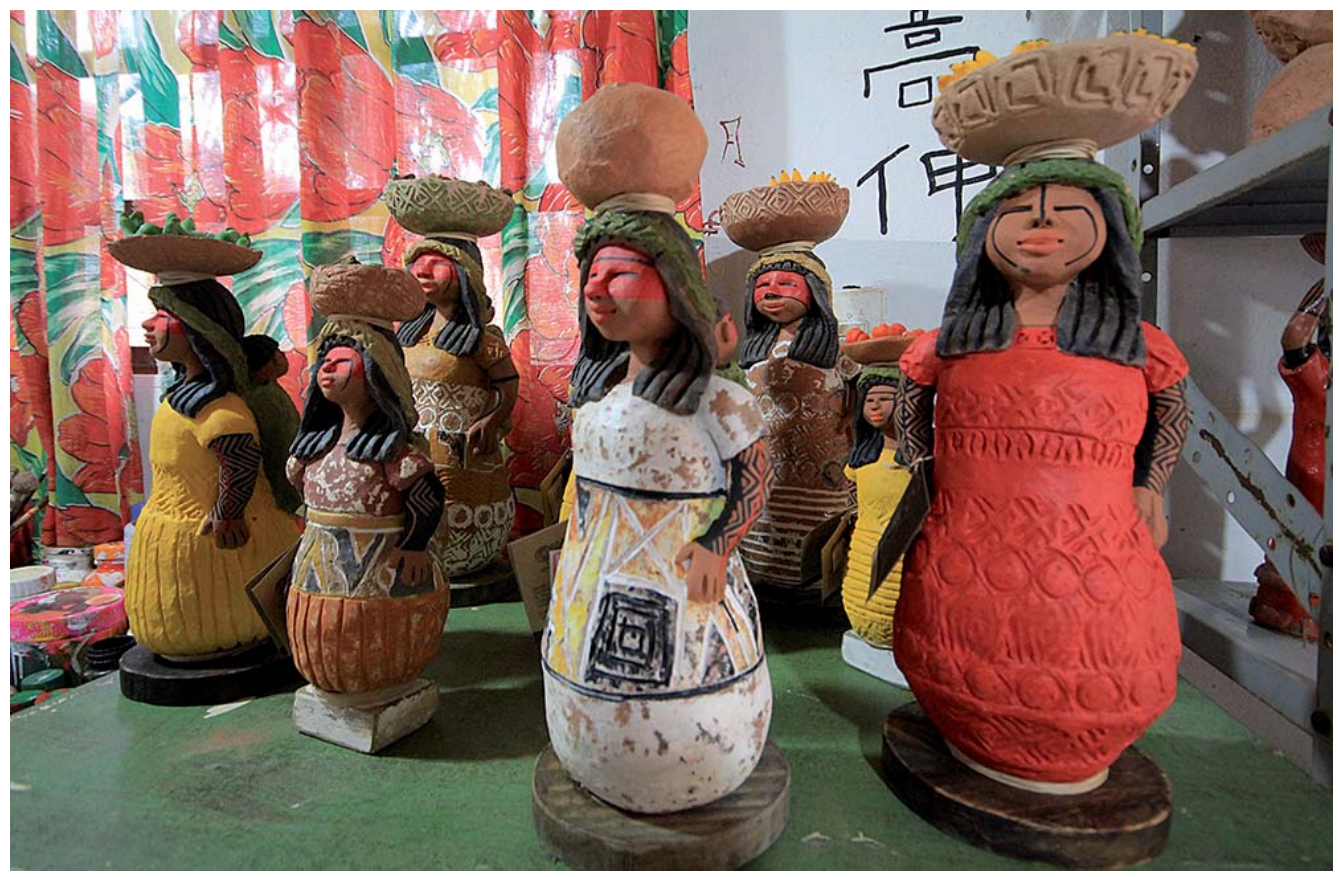

Figura 4- Artesanato sul-mato-grossense de Indiana Marques Fonte: FMCS (2016). Foto: Edemir Rodrigues. 


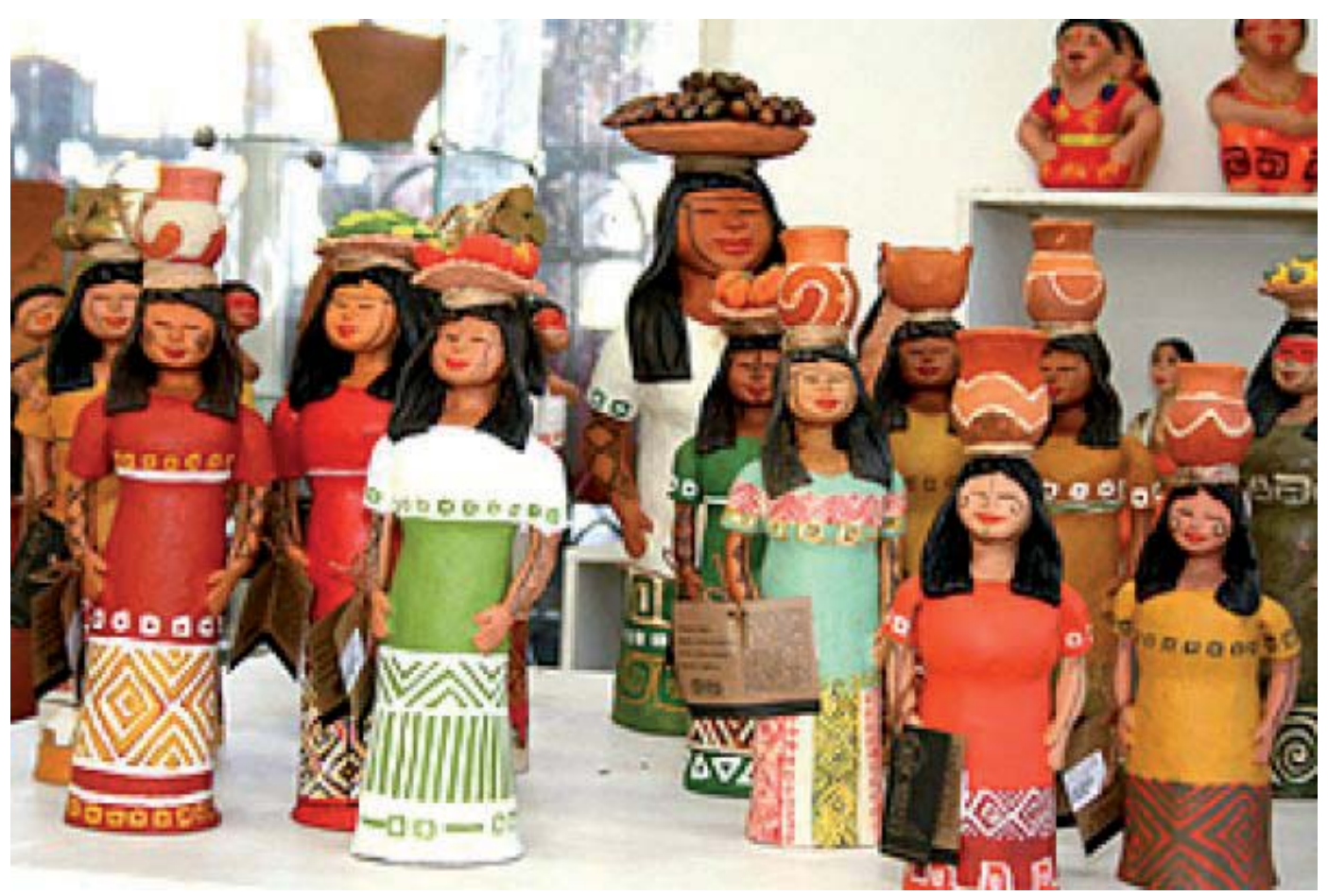

Figura 5- Artesanato sul-mato-grossense de Indiana Marques Fonte: <http://www.gazetadopantanal.com/wp-content/uploads/cache/38437_BnHover.jpg>. Acesso em: 10 mar. 2016

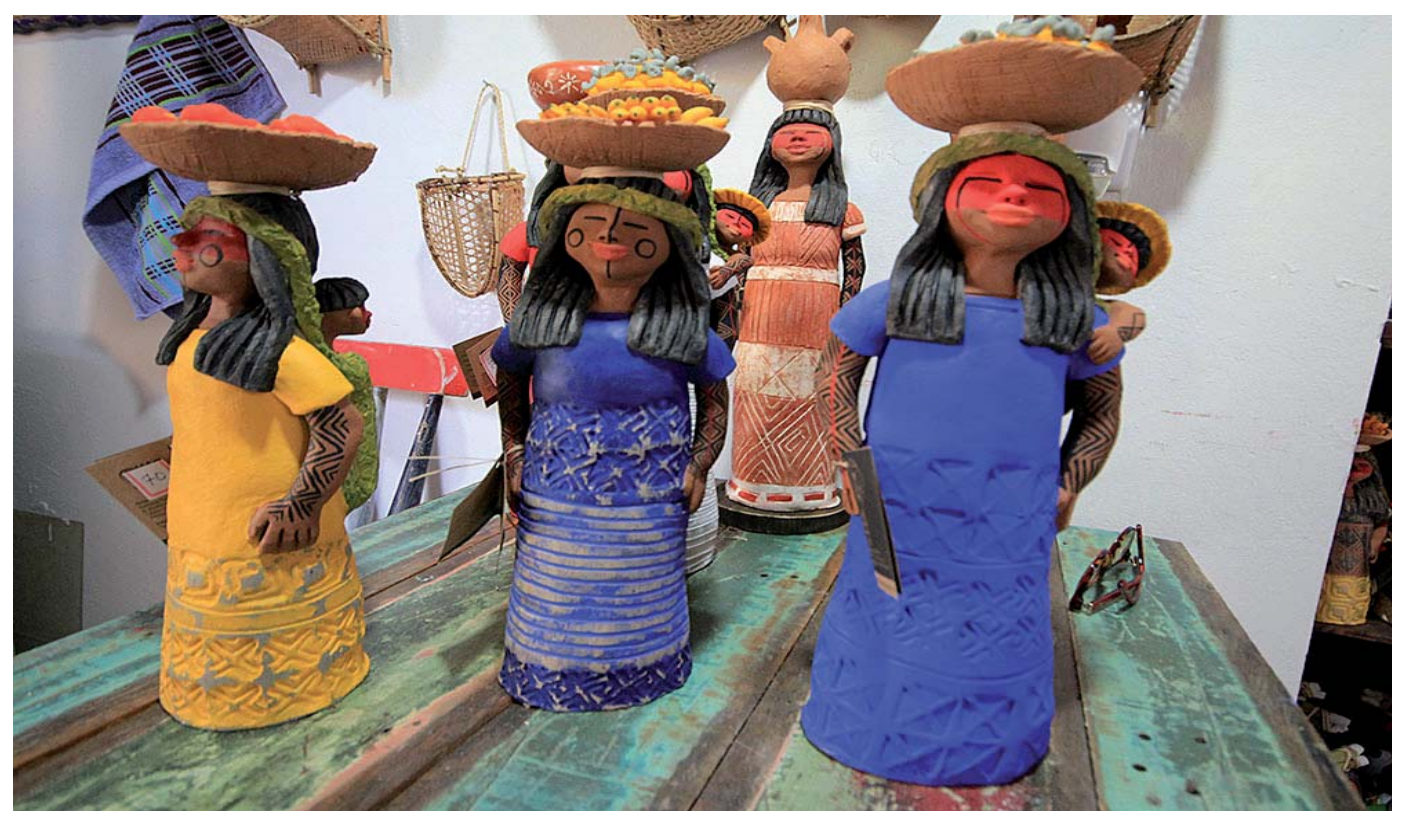

Figura 6- Artesanato sul-mato-grossense de Indiana Marques Fonte: FMCS (2016). Foto: Edemir Rodrigues. 


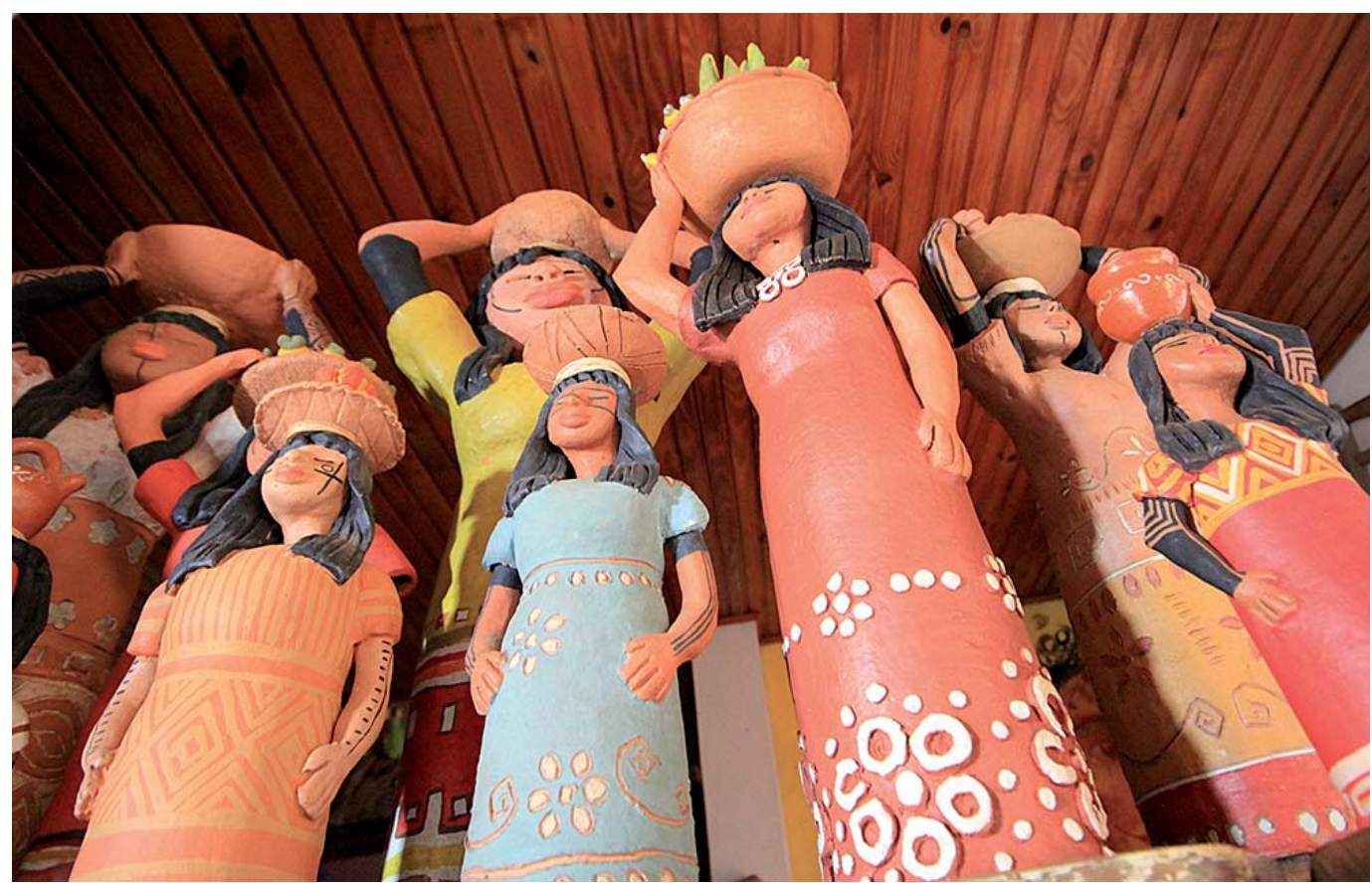

Figura 7- Artesanato Sul-mato-grossense de Indiana Marques Fonte: FMCS (2016). Foto: Edemir Rodrigues.

Dessa forma, pode-se identificar a importância do artesanato sul-mato-grossense, estimulando o turismo e o conhecimento da cultura material e imaterial, bem como sendo fonte de renda e de inclusão social, contribuindo assim para o desenvolvimento sustentável.

\section{CONSIDERAÇÕES FINAIS}

Os conceitos de artesanato ressaltam esse fazer como uma atividade predominantemente manual que exige criatividade e habilidade pessoal. É uma manifestação de vida em sociedade, construção que se compõe no sentido de produzir bens que tenham a função utilitária, lúdica, decorativa ou religiosa. Logo, o resultado do fazer do artesão pode ser tido como um testemunho vivo de uma determinada cultura por meio de sua representatividade.

Tal a complexidade de matizes do artesanato brasileiro, é difícil classificá-lo, pura e simplesmente, mas a maioria dos estudos, incluindo pesquisas do SEBRAE/Brasil, agrupa o artesanato nas seguintes categorias: arte popular, trabalhos manuais e artesanato de pequeno montante, porém em séries.

Em Mato Grosso do Sul, há uma grande oferta de matéria-prima para o fabrico de peças artesanais: madeiras, osso, cerâmica variada, lã- para as tecelagens, capim (como a taboa), couro, inclusive de peixes, que modelam a riqueza cultural do artesanato do centro-oeste, formando uma linguagem cultural plural, tal como a formação dos habitantes de MS.

As etnias indígenas, das quais se destacam a Terena e a Kadiweu, são exemplos materiais das representações simbólicas que estão agregadas em cada peça produzida por indígenas. Na maioria as peças indígenas são artesanatos de cerâmica, que trazem, em cada pequena peça, o valor cultural de todo o saber de seu povo de modo subliminar. Na atualidade, as peças artesanais se integram às peças industriais para comporem decorações com alto valor cultural agregado, a 
herança da cultura imaterial das etnias indígenas e a riqueza plural de cores e sabores da América Latina, pontuada nas influências positivas da identidade fronteiriça - da Bolívia e do Paraguai, que compõem o caleidoscópio cultural sul-mato-grossense.

\section{REFERÊNCIAS}

DA MATTA, Roberto. O que faz o Brasil, Brasil. Rio de Janeiro: Rocco, 2006.

DOLABELLA, Renato Melo et al. Arte plumária: índios brasileiros. Belo Horizonte: Grupo de Estudo do Projeto Experimental Artesanato/UFMG, s/d.

FUNDAÇÃO DE CULTURA DE MATO GROSSO DO SUL (FUCMS). Trabalhos da Artesã Indiana Marques - galeria. 28 de junho de 2016. Disponível em: <http://www.fundacaodecultura.ms.gov.br/trabalhos-daartesa-indiana-marques/>. Acesso em: 6 mar. 2017.

Centro referencial de artesanato de Mato Grosso do Sul. Campo Grande, MS: FCMS, 2008.

GEERTZ, Clifford. A transição para a humanidade. Rio de Janeiro: Fundo de Cultural, 1996.

HOLANDA, Sérgio Buarque de. História da civilização. São Paulo: Companhia Nacional, 2009.

KASHIMOTO, Emília Mariko; MARINHO, Marcelo; RUSSEF, Ivan. Cultura, identidade e desenvolvimento local: conceitos e perspectivas pra regiões em desenvolvimento. Interações - Revista Internacional do Desenvolvimento Local, Campo Grande, MS, v. 3, n. 4, p. 35-42, mar. 2002.

LARAIA, Roque de Barros. Cultura um conceito antropológico. Rio de Janeiro: Zahar, 2006.

LIMA, Tânia Andrade. Cerâmica indígena brasileira. In: RIBEIRO, Darcy (Ed.). Suma etnológica brasileira. Petrópolis, RJ: Vozes, 1987. v. 2: Tecnologia indígena.

MARQUES, Indiana. A cultura na equação da economia: arrojo para superar limites. Revista Cultura-MS, Campo Grande, MS, n. 1, 2008.

MATO GROSSO DO SUL [Estado]. Decreto n. 12.847, de 16 de novembro de 2009. Cerâmica Terena - MS - registro do patrimônio imaterial. Campo Grande, MS, 2009.

Lei n. 3.522, de 30 de maio de 2008. Dispõe sobre a proteção do patrimônio histórico, artístico e cultural de Mato Grosso do Sul. Campo Grande, MS, 2008.

ORGANIZAÇÃO DAS NAÇÕES UNIDAS PARA A EDUCAÇÃO, A CIÊNCIA E A CULTURA (UNESCO). Políticas culturais para o desenvolvimento: uma base de dados para a cultura. Brasília: UNESCO Brasil, 2003. 236 p.

PELLEGRINI, Fábio (Org.). Vozes do artesanato. Campo Grande, MS: FCMS, 2011.

SOUZA, Sandra Cristina de. Mulheres Terena: história e cotidiano. 2000. 82f. Dissertação (Mestrado em História) - Pontifícia Universidade Católica de São Paulo, São Paulo, 2000.

ZURUTUZA, Anahí. Indiana Marques. In: PELEGRINI, Fábio (Org.). Vozes do artesanato. Campo Grande, MS: FCMS, 2011.

\section{Sobre as autoras:}

Maria Augusta Castilho: Docente no Programa de Pós-Graduação em Desenvolvimento LocalMestrado/Doutorado e do Curso de Graduação em História da Universidade Católica Dom Bosco (UCDB), Campo Grande, MS. E-mail: m.a.castilho@terra.com.br

Arlinda Cantero Dorsa: Doutora em Língua Portuguesa, Mestre em Comunicação e Letras. Docente no Programa de Pós-Graduação- Mestrado e Doutorado em Desenvolvimento Local da UCDB. E-mail: acdorsa@ucdb.br 
Maria Christina Lima Félix Santos: Mestre em Desenvolvimento Local. Doutoranda em Desenvolvimento Local- Bolsista Capes/PROSUP/UCDB-MS. E-mail: mclfs@yahoo.com.br

Monizzi Mábile Garcia Oliveira: Graduanda do 7o semestre do Curso de História da UCDB. Bolsista CNPq-PIBIC do Laboratório de História da UCDB. E-mail: monizzi.mg@gmail.com 